\title{
Increase of Temperature and Salinity in the Active Layer of the North-Eastern Black Sea from 2010 to 2020
}

\author{
O. I. Podymov ${ }^{凶}$, A. G. Zatsepin, V. V. Ocherednik \\ Shirshov Institute of Oceanology, Russian Academy of Sciences, Moscow, Russian Federation \\ \uravela@yahoo.com
}

\begin{abstract}
Purpose. The paper is aimed at assessing salinity and temperature variability in the upper 300-meter layer of the northeastern part of the Black Sea based on the analysis of the archival and modern expeditionary data.

Methods and Results. The data on the cross-sections "coast - sea center" (with the length of 70-110 nautical miles) performed from 1999 to 2009, as well as the results of regular ship monitoring in the shelf-slope zone of the northeastern part of the Black Sea carried out in 2010-2020 were used. It was found that salinity was progressively increasing in the upper 200-meter layer during the last decade. Salinity increase, on the average, constituted annually about 0.05-0.06 PSU. An increase of temperature was also observed below the layer of temperature minimum (core of the cold intermediate layer). In particular, the lower $8.7^{\circ} \mathrm{C}$ isotherm rose annually, on the average, by $11 \mathrm{~m}$ from its annual average depth $242 \mathrm{~m}$ in 2010 up to $121 \mathrm{~m}$ in 2020. Salinity growth led to the corresponding changes in water density that resulted in elevation of the lower boundary of the oxygen-containing layer (potential density is 15.8) from the depth of $143 \mathrm{~m}$ in 2010 to $124 \mathrm{~m}$ in 2020.

Conclusions. Climatic changes have led to a noticeable salinity increase in the upper 200-meter layer of the northeastern Black Sea, as well as to a temperature increase in the layers situated below the temperature minimum layer. Though the measurements were carried out in a certain area of the shelf-slope zone, there are reasons to assume that the observed dynamics can be attributed to the entire Black Sea. Physical reasons for the observed changes require a detailed research.
\end{abstract}

Keywords: Black Sea, salinity, temperature, climatic changes

Acknowledgments: the study was carried out within the framework of the state task No. 0149-20190014 (expeditions and data collection) and with the support of the RFBR grant No. 20-05-00167 (processing and analysis).

For citation: Podymov, O.I., Zatsepin, A.G. and Ocherednik, V.V., 2021. Increase of Temperature and Salinity in the Active Layer of the North-Eastern Black Sea from 2010 to 2020. Physical Oceanography, [e-journal] 28(3), pp. 257-265. doi:10.22449/1573-160X-2021-3-257-265

DOI: $10.22449 / 1573-160 X-2021-3-257-265$

(C) O. I. Podymov, A. G. Zatsepin, V. V. Ocherednik, 2021

(C) Physical Oceanography, 2021

\section{Introduction}

In the last decade, warm winters have become a climatic norm for the Black Sea. Climate warming and atmospheric circulation restructuring lead to a change in the thermohaline structure formation processes in the upper aerobic layer of the sea [1]. Regular observations on the 9 nautical miles cross-section, carried out by the Southern Branch of Shirshov Institute of Oceanology, Russian Academy of Sciences (SB SIO RAS) in the Gelendzhik region, showed the disappearance of the cold intermediate layer (CIL) as it was originally defined (water temperature less than $8{ }^{\circ} \mathrm{C}$ ) and a significant increase in temperature and salinity in the upper sea layer (from the surface down to 200-300 m) in 2010-2020.

The paper provides a brief description of the thermohaline structure changes, based on the analysis of data from the regular ship monitoring of the Black Sea ISSN 1573-160X PHYSICAL OCEANOGRAPHY VOL. 28 ISS. 3 (2021) 
shelf-slope zone, and hypotheses about the causes of these changes. The ship monitoring is a part of the SIO RAS annual program of the complex scientific studies in the Black Sea.

\section{Region and methods of the research}

Comprehensive hydrophysical and environmental monitoring by the SB SIO RAS has been carried out since mid-2009 [2, 3]. The studies are performed once every 2-4 weeks, depending on the season (more often from May to October). From late December to early April, the ship studies are stopped, save for occasional expeditions. For hydrophysical measurements, an SBE 19Plus CTD probe (Sea-Bird Electronics) was used, installed on a Rosetta SBE 32 sampler that transmits real-time data via a conducting cable and an SBE 33 deck unit. The study area is shown in Fig. 1. Probing was carried out to the bottom (on the shelf and continental slope) or to a depth of $300 \mathrm{~m}$ in the deep sea area.

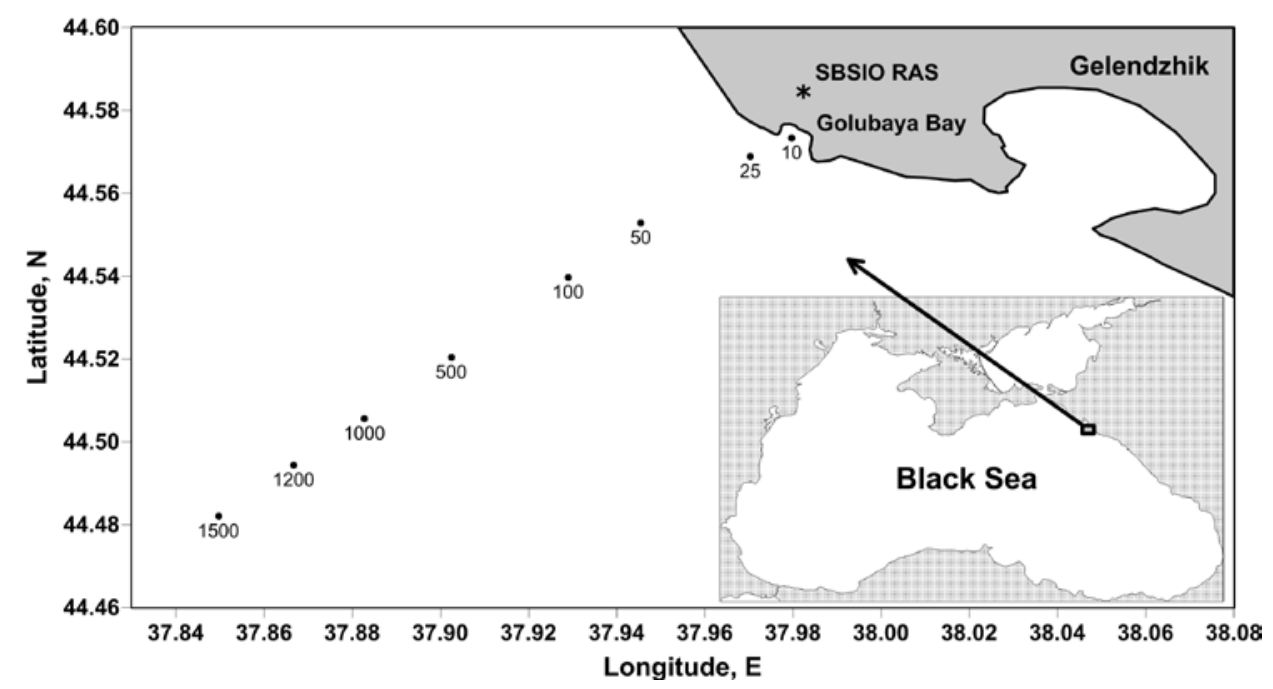

F i g. 1. The study site of the long-term monitoring in the northeastern Black Sea. The numbers show the maximum depth at each station

In total, there were about 250 monitoring expeditions during 2010-2020. The analysis also included the archival data of studies on the Gelendzhik - center of the sea cross-sections, carried out by the SIO RAS relatively regularly from the beginning of 1999 to 2009 using similar equipment (SBE 19Plus probe) for hydrophysical measurements. Archival data were taken for the station located in the middle of the monitoring cross-section (500 $\mathrm{m}$ depth).

\section{Results}

The dynamics of long-term changes in salinity and temperature at stations with depths of 25, 50 and $500 \mathrm{~m}$ was studied. At the shelf stations, layers of $0-25 \mathrm{~m}$ (upper mixed layer, hence UML) and 25-50 m (seasonal thermocline) were analyzed. For the $500 \mathrm{~m}$ depth station, changes were also analyzed in the main pycnocline $(70-150 \mathrm{~m})$ and in the layer below it (180-250 m). Fig. 2 shows 
a diagram of long-term salinity changes for the $500 \mathrm{~m}$ depth station; a similar picture was observed at the shelf stations.
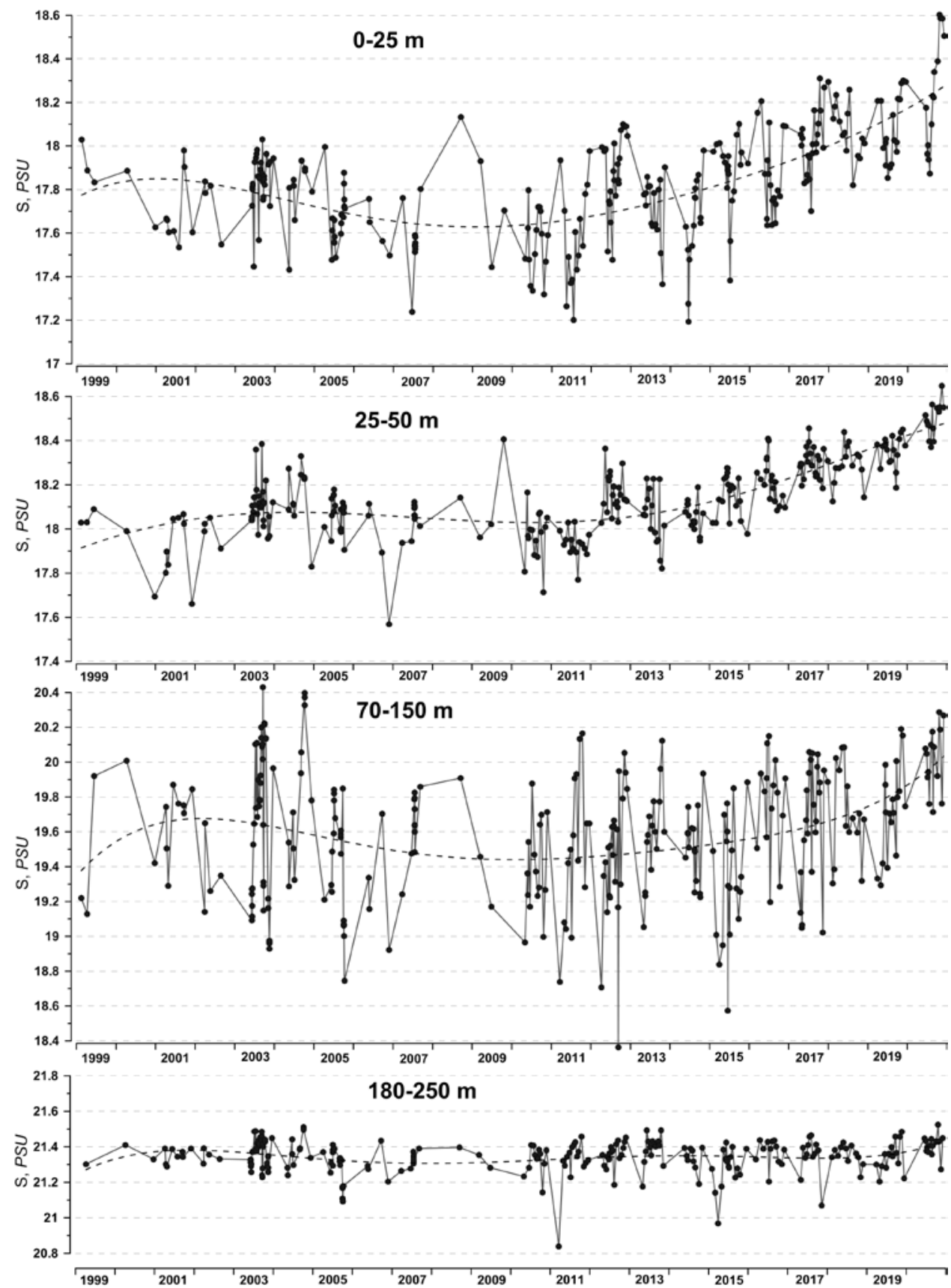

F i g. 2. Salinity at the $500 \mathrm{~m}$ depth station averaged for different depth ranges from 1999 to 2020 (each dot indicates a separate profile; the dotted line is a polynomial fit) 
It should be noted that hydrophysical structure in the Black Sea in the main pycnocline layer and in the underlying layers is subject to significant vertical fluctuations [4, 5], both short-term (within a few days) and seasonal ones [6]. For this reason, it would be difficult to trace the long-term dynamics of salinity and temperature at individual depths with a small number of occasional studies or over a short period. Therefore, the salinity values were calculated in the selected layers.

According to Fig. 2, a slight decrease in salinity was observed in the upper $150 \mathrm{~m}$ layer from 2001 to 2009, and after that its visible growth began. It should be noted that quasi-cyclic changes in salinity were observed in the Black Sea before. They were mentioned in $[7,8]$, along with the surface salinity increase that started in 2009, and these changes were attributed primarily to fluctuations in the climatic regime of the Black Sea.

In the layer located under the main pycnocline, salinity had no pronounced changes, remaining approximately at the same level, which somewhat contradicts a number of previous studies [9-12], where a constant increase in deep salinity was noted. The mean annual increase in salinity in the layers of $0-25,25-50$ and 70-150 m was 0.05-0.06 PSU, and over a ten-year period, the salinity in these layers thus increased by $0.5-0.6 \%$.

Since it is salinity that contributes the most to water density in the layers below the thermocline, it would be reasonable to expect a corresponding rise of isopycnals. And indeed it was observed. For example, the isopycnal of 15.8, below which oxygen practically disappears and the redox layer begins $[13,14]$, rose from 2010 to 2019 on average from a depth of $143 \mathrm{~m}$ to $134 \mathrm{~m}$. In 2020 an even more noticeable jump was observed - up to $124 \mathrm{~m}$. Although in 2020, due to the Covid19 pandemic, no spring field studies were carried out, the analysis of the data obtained from June to December has shown that hydrogen sulfide boundary rised by an average of $6 \mathrm{~m}$ compared to the same period in 2019. Thus, one of the consequences of such dynamics of salinity and water density is a decrease in the thickness of the active (productive) oxygen-containing layer.

Beside the salinity increase, temperature was also rising in the layer below the temperature minimum layer (Fig. 3). Since the temperature at those depths is always higher than in the minimum layer, its increase is not directly related to atmospheric warming and heat flux from the surface due to diapycnal mixing. Obviously, the heat source should be located in the layer of the main pycnohalocline and in the layers below it.

In 2010-2020, the lower isotherm of $8.7^{\circ} \mathrm{C}$ rose at an average rate of $11 \mathrm{~m}$ per year, from an average depth of $242 \mathrm{~m}$ in 2010 to an average depth of $159 \mathrm{~m}$ in 2019 and $121 \mathrm{~m}$ in 2020. The abnormal jump over the past year may have been due in part to the aforementioned limited data statistics. Nevertheless, the rate of rise of isotherms has noticeably increased since 2018. 


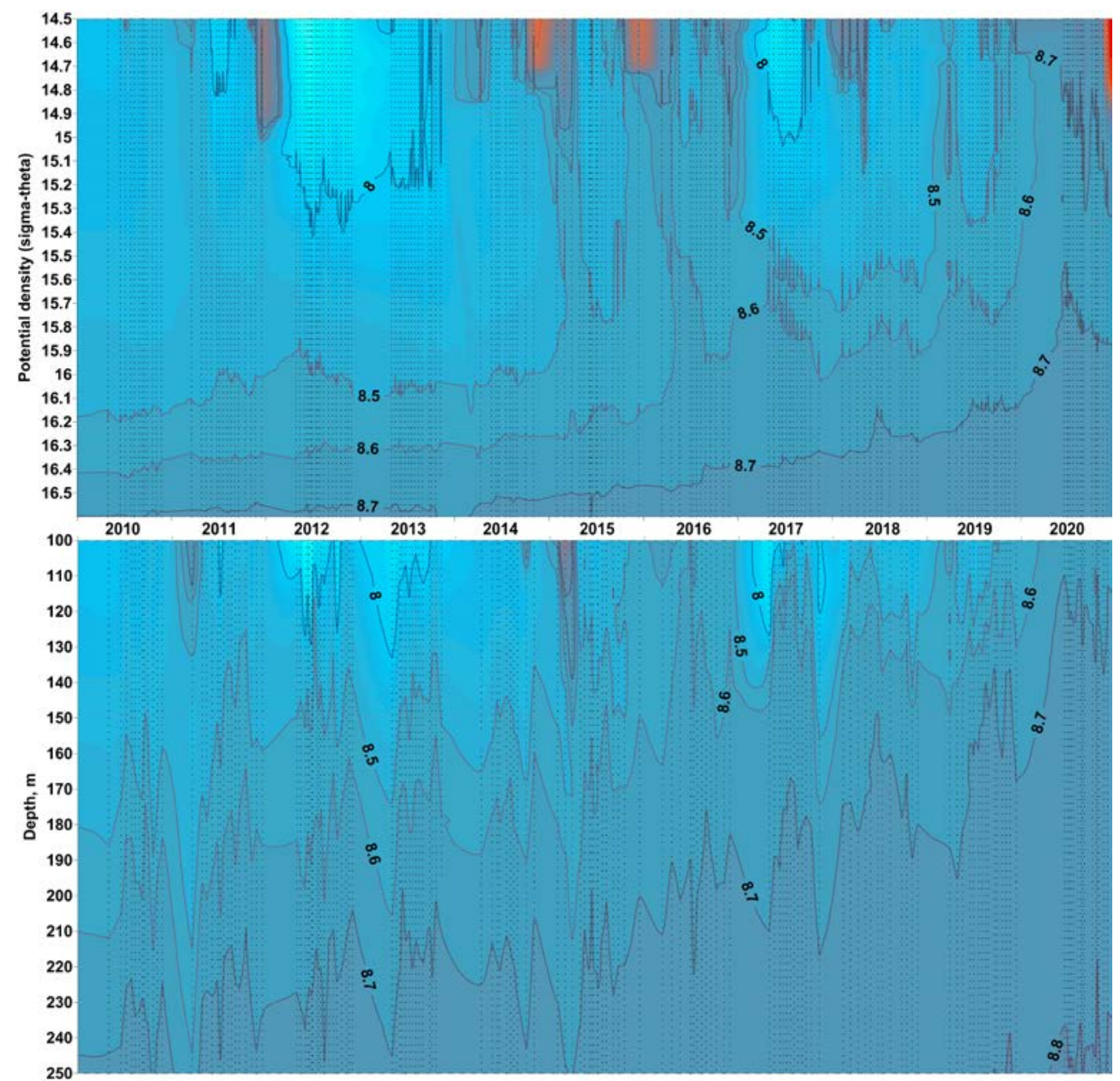

F i g. 3. Isotherm dynamics from 2010 to 2020 in the fields of potential density (above) and depth (below). Vertical dotted lines correspond to the dates of actual measurements

A significant change in temperature and salinity in the upper 200-300 m layer is also shown by the T-S diagrams for the upper layer from 50 to $300 \mathrm{~m}$ depth in 2010 and 2020 (Fig. 4), as well as the mean profiles of salinity and temperature for individual years of this ten-year period (Fig. 5). These figures also show that along with salinization and water warming downward from the surface, salinity and temperature were increasing in the layer of the main pycno-halocline and even in the layers lying below it. 


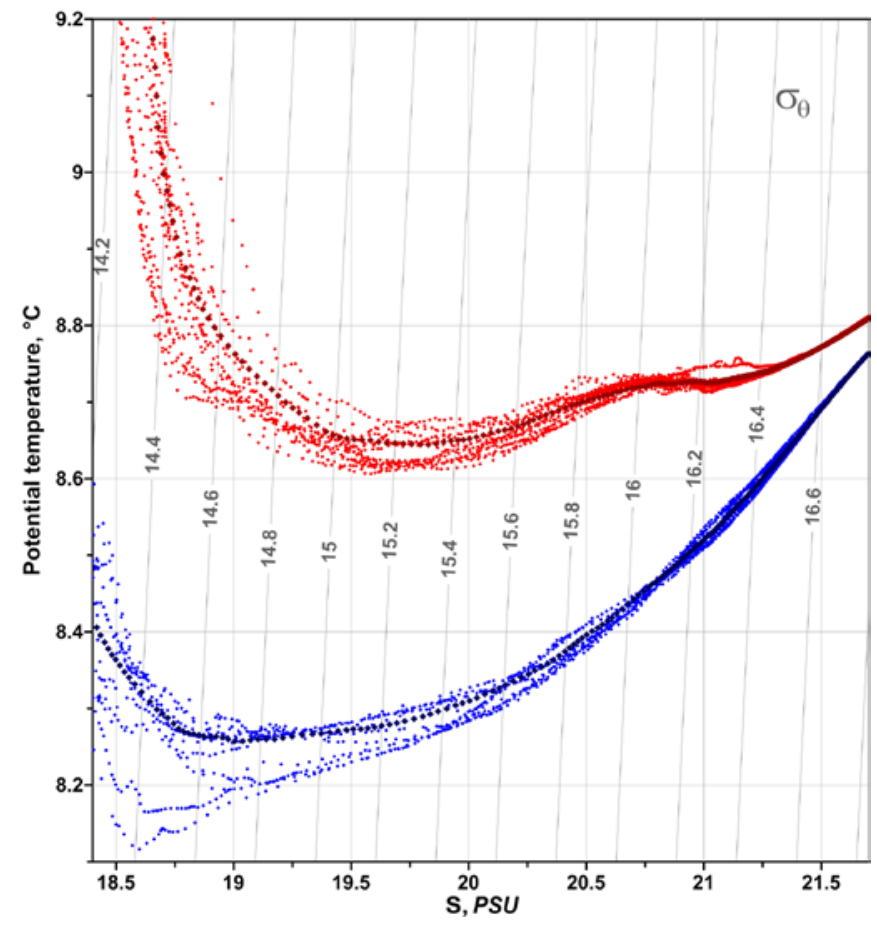

F i g. 4. T-S diagrams of the Black Sea water in the upper 300 meter layer in 2010 (blue color) and in 2020 (red color). Thin dotted lines show individual CTD-profiles, bold dotted line - annual average profile
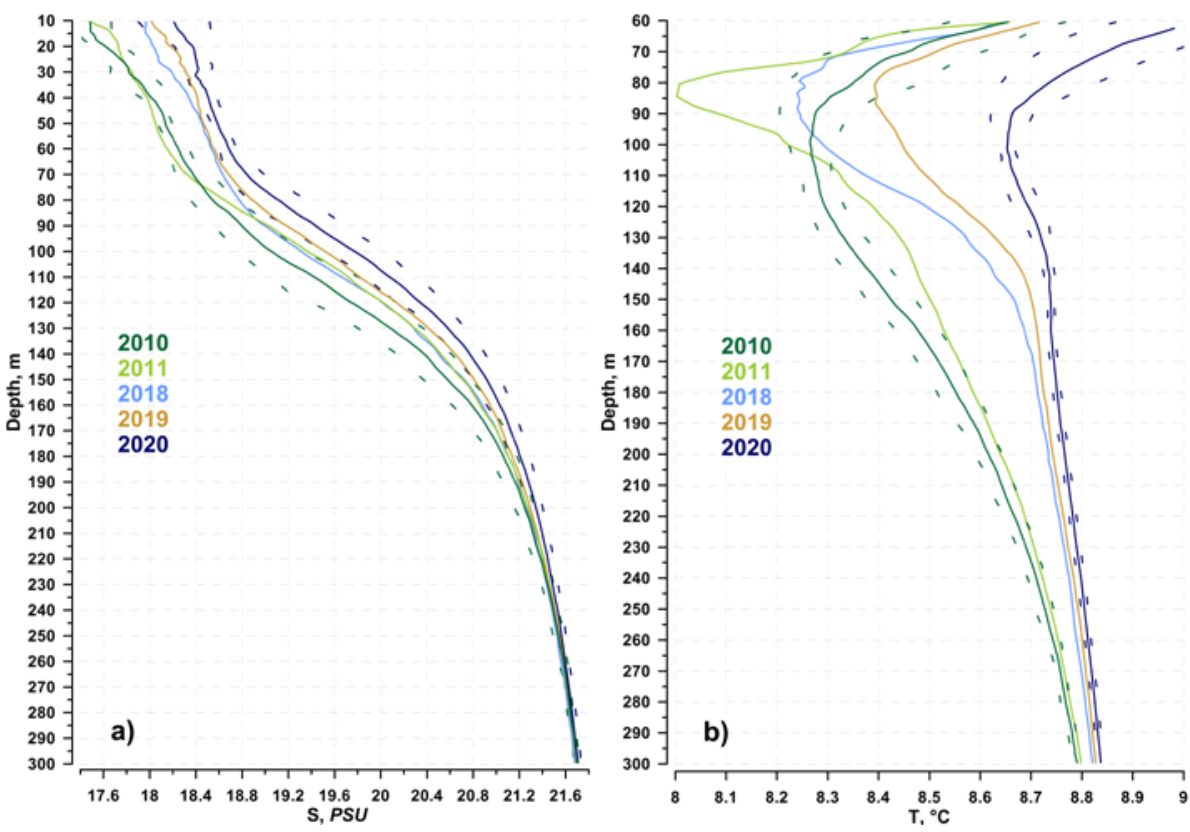

F i g. 5. Changes in the mean profiles of salinity ( $a$ ) and temperature $(b)$ in the upper $300 \mathrm{~m}$ layer of the Black Sea from 2010 to 2020. Dotted lines denote standard deviations of the temperature and salinity annual average profiles in 2010 and 2020 


\section{Discussion}

A warming of the regional climate, a decrease in river runoff and precipitation over the water area lead to an increase in the temperature of the upper layer of the Black Sea and salinization of its waters downward from the surface, which is described in the literature $[7,9,15]$. The process of an increase in the temperature of the upper layer and CIL began in 2009, proceeding progressively with two interruptions caused by the cold winters of 2011/12 and 2016/17.

At the same time, the data given in the present paper indicate a progressive increase in salinity and temperature in the main pycno-halocline and the layer located below it. The reason for this may be an increase in the inflow of water from the lower Bosporus current into a layer of water with a potential density of 14.6-16.2 and, possibly, into deeper layers. However, an accurate explanation of the phenomenon of temperature and salinity increase requires additional data and deeper analysis.

An important issue that should be discussed in this paper is how the observed increase in salinity affects the vertical stability of water in the upper 40-80 m layer, which is subject to winter convective mixing. Obviously, an increase in salinity downward from the surface should reduce vertical stability and promote the development of convection due to winter cooling. However, the data analysis shows that the increase in salinity was approximately the same in the upper 120-130 m water layer and the mean annual salinity profile showed a uniform increase from 2010 to 2020 (Fig. 5, a). This means that the vertical salinity gradient in this layer has remained almost constant during all these years and its contribution to the vertical stability has not changed significantly over the last decade.

In the present paper, the ongoing changes in the thermohaline structure of water in a particular part of the Black Sea were described. However, taking into account the high speed of horizontal (isopycnic) mixing of the Black Sea water and that its time constant in the upper layer is about 6 months [16], it can confidently be assumed that the temperature and salinity increase trend in the upper 200-300 meter layer, shown in this paper for the last decade, is typical for the entire Black Sea area. Nevertheless, this issue requires further research based on the analysis of data from Argo buoys and ship-borne CTD measurements in the deep-water part of the sea.

\section{REFERENCES}

1. Stanev, E.V., Peneva, E. and Chtirkova, B., 2019. Climate Change and Regional Ocean Water Mass Disappearance: Case of the Black Sea. Journal of Geophysical Research: Oceans, 124(7), pp. 4803-4819. https://doi.org/10.1029/2019JC015076

2. Zatsepin, A.G., Ostrovskii, A.G., Kremenetskiy, V.V., Nizov, S.S., Piotukh, V.B., Soloviev, V.A., Shvoev, D.A., Tsibul'sky, A.L., Kuklev, S.B. [et al.], 2014. Subsatellite Polygon for Studying Hydrophysical Processes in the Black Sea Shelf-Slope Zone. Izvestiya, Atmospheric and Oceanic Physics, 50(1), pp. 13-25. https://doi.org/10.1134/S0001433813060157

3. Arashkevich, E.G., Louppova, N.E., Nikishina, A.B., Pautova, L.A., Chasovnikov, V.K., Drits, A.V., Podymov, O.I., Romanova, N.D., Stanichnaya, R.R. [et al.], 2015. Marine Environmental Monitoring in the Shelf Zone of the Black Sea: Assessment of the Current State 
of the Pelagic Ecosystem. Oceanology, 55(6), pp. 871-876. https://doi.org/10.1134/S0001437015060016

4. Zatsepin, A.G., Elkin, D.N., Korzh, A.O., Kuklev, S.B., Podymov, O.I., Ostrovskii, A.G. and Soloviev, D.M., 2016. On Influence of Current Variability in the Deep Black Sea upon Water Dynamics of Narrow North Caucasian Continental Shelf. Physical Oceanography, (3), pp. 1422. https://doi.org/10.22449/1573-160X-2016-3-14-22

5. Ostrovskii, A.G. and Zatsepin, A.G., 2011. Short-Term Hydrophysical and Biological Variability over the Northeastern Black Sea Continental Slope as Inferred from Multiparametric Tethered Profiler Surveys. Ocean Dynamics, 61(6), pp. 797-806. https://doi.org/10.1007/s10236-011-0400-0

6. Podymov, O.I. and Zatsepin, A.G., 2016. Seasonal Anomalies of Water Salinity in the Gelendzhik Region of the Black Sea according to Shipborne Monitoring Data. Oceanology, 56(3), pp. 342-354. https://doi.org/10.1134/S0001437016020156

7. Polonskii, A.B. and Lovenkova, E.A., 2006. Long-Term Trends in the Variability of DeepWater Thermohaline Characteristics of the Black Sea. Physical Oceanography, 16(4), pp. 203215. https://doi.org/10.1007/s11110-006-0026-9

8. Belokopytov, V.N., 2014. [Climatic Variability of the Black Sea Density Structure]. Ukrainian Hydrometeorological Journal, (14), pp. 227-235. Available at: http://uhmj.odeku.edu.ua/klimaticheskaya-izmenchivost-plotnostnoj-struktury-chernogomorya/ [Accessed: 15 May 2021] (in Russian).

9. Blatov, A.S., Kosarev, A.N. and Tuzhylkin, V.S., 1980. Variability of the Hydrological Structure of the Black Sea Water and Its Connection with Outer Factors. Vodnye Resursy, (6), pp. 71-82 (in Russian).

10. Tsimplis, M.N., Josey, S.A., Rixen M. and Stanev, E.V., 2004. On the Forcing of Sea Level in the Black Sea. Journal of Geophysical Research: Oceans, 109(C8), C08015. https://doi.org/10.1029/2003JC002185

11. Polonsky, A.B. and Shokurova, I.G., 2013. Long-Term Variability of Temperature and Salinity in the Black Sea and Its Causes. Reports of the National Academy of Sciences of Ukraine, (1), pp. 105-110 (in Russian).

12. Polonsky, A.B., Shokurova, I.G. and Belokopytov, V.N., 2013. Decadal Variability of Temperature and Salinity in the Black Sea. Morskoy Gidrofizicheskiy Zhurnal, (6), pp. 27-41 (in Russian).

13. Rozanov, A.G., 1995. Redox Stratification in the Black Sea Water. Okeanologiya, 35(4), pp. 544-549 (in Russian).

14. Stunzhas, P.A., 2000. On the Structure of the Zone of Interaction of Aerobic and Anaerobic Waters of the Black Sea on the Basis of Measurements with a Membrane-Free Sensor of Oxygen. Oceanology, 40(4), pp. 503-509.

15. Altman, E.N. and Kumysh, N.I., 1986. [Long-term Annual Variability of Freshwater Balance in the Black Sea]. In: SOI, 1986. Trudy GOIN = SOI`s Proceedings. Issue 176, pp. 3-18 (in Russian).

16. Zhurbas, V.M., Zatsepin, A.G., Grigor'eva, Yu.V., Eremeev, V.N., Kremenetsky, V.V., Motyzhev, S.V., Poyarkov, S.G., Poulain, P.-M., Stanichny, S.V. and Soloviev, D.M., 2004. Water Circulation and Characteristics of Currents of Different Scales in the Upper Layer of the Black Sea from Drifter Data. Oceanology, 44(1), pp. 30-43.

About the authors:

Oleg I. Podymov, Senior Research Associate, Laboratory of Hydrophysics and Modeling, Shirshov Institute of Oceanology, Russian Academy of Sciences (36 Nahimovskiy prospekt, Moscow, 117997, Russia), Ph. D. (Phys.-Maths), SPIN-code: 1471-9272, Author ID: 134840, ORCID ID: 0000-0002-6591-9160, huravela@yahoo.com 
Andrey G. Zatsepin, Head of the laboratory, Shirshov Institute of Oceanology, Russian Academy of Sciences (36 Nahimovskiy prospekt, Moscow, 117997, Russia), Dr. Sci. (Physics\&Maths), ORCID ID: 0000-0002-5527-5234, zatsepin@ocean.ru

Vladimir V. Ocherednik, Junior Research Associate, Laboratory of Hydrophysics and Modeling, Shirshov Institute of Oceanology, Russian Academy of Sciences (36 Nahimovskiy prospekt, Moscow, 117997, Russia), ORCID ID: 0000-0002-3593-7114, v.ocherednik@ocean.ru

Contribution of the co-authors:

Oleg I. Podymov - conceptualization, field studies, calculations, original draft, visualization

Andrey G. Zatsepin - methodology, discussion, manuscript review \& editing

Vladimir V. Ocherednik - conceptualization, data analysis, field studies

All the authors have read and approved the final manuscript.

The authors declare that they have no conflict of interest. 